\title{
Analysis of effects from usage of skeletal anchorage-assisted Pendulum appliance on vertical component of craniofacial structure
}

\author{
Jin-Woo Lee* \\ Department of Orthodontics, College of Dentistry, Dankook University, Cheonan, Republic of Korea
}

Purpose: The purpose of this study was to evaluate distalizing effects from the Pendulum appliance on vertical component of craniofacial structures. Materials and Methods: 20 Patients who visited for orthodontic treatments are assigned to two groups. Group I, SN-MP > 37 degrees are showing hyperdivergent pattern. Group II, $29<$ SN-MP < 37 degrees are showing mesocephalic pattern. Each group are consisted of 10 people. Results and Conclusions: Differences between skeletal classifications result in significant differences at labioversion of lower incisors and distalized amount, which is larger at Group I ( $P<.05)$. Group II has only shown significant distalized molars $(P<.05)$. Labioversion of lower incisors has not shown significant change. Skeletal anchorageassisted Pendulum appliance doesn't deteriorate vertical component nor significantly improve. (J Dent Rehabil Appl Sci 2018;34(1): 10-6)

Key words: skeletal anchorage-assisted; Pendulum appliance; vertical component of craniofacial structures

\section{서론}

상악 구치의 후방 이동은 상악의 골격성, 치아치조성 돌출 치료에서 필수적인 과정이다. 과거 연구에서 구외 장치를 이용하거나, 펜둘럼 장치, 가철식 교정 장치, 악간 고무줄, 자석 등에 대한 방법 등이 소개되었다. ${ }^{1-4}$ 상악 구 치를 후방 이동함으로써 발치를 거부하는 환자에서 어려 울 수 있는 치료의 대안이 될 수 있으며, 부적절한 발치로 인한 상, 하순이 과도하게 견인되는 부작용을 막을 수 있 다.

Pendulum appliance는 상악 제1대구치의 후방 이동을 가능하게 함으로써 2급 구치 관계를 수정할 수 있는 장 치이며, 환자의 협조도가 필요하지 않으며, 상악의 확장

\footnotetext{
${ }^{*}$ Correspondence to: Jin-Woo Lee

Professor, Department of Orthodontics, College of Dentistry, Dankook University 119 Dandae-ro, Dongnam-gu, Cheonan, 31116, Republic of Korea Tel: +82-41-550-0114, Fax: +82-41-550-0233, E-mail: jwlee@dankook.ac.kr Received: August 31, 2017/Last Revision: September 8, 2017/Accepted: December 18,2017
}

효과도 얻을 수 있다. ${ }^{3}$ 하지만 구치의 후방이동시 고정원 의 상실, 비조절성 경사 이동 등 부작용이 존재하였다. ${ }^{5}$ 최근의 골격성 임시 고정원의 사용으로 절대적인 후방 이 동이 가능하게 되었다.

임시 고정원과 Pendulum 장치를 동반하여 사용하는 치료 방식에 대해 다수의 연구가 보고되었다..$^{6-17}$ 치료 효 과에 대해 시상적 관계의 개선에 더불어, 수직적 요소에 구치의 후방 이동이 주는 영향에 대한 연구는 보고된 바 가 없다. 본 연구의 목적은 상악 구치의 후방 이동이 발산 형 안모와, 중간형 안모의 환자 군에 미치는 영향을 분석 하여 이후 치료에 참고로 하기 위함이며, 귀무 가설은 발 산형 안모와 중간형 안모에 미치는 상악 구치의 후방이 동은 유의한 영향을 주지 않는다이다.

Copyright $(2018$ The Korean Academy of Stomatognathic Function and Occlusion. (c) It is identical to Creative Commons Non-Commercial License. 


\section{연구 재료 및 방법}

이 연구는 단국대학교 임상시험위원회(DKUDH IRB) 의 승인을 받아 진행하였다(DKUDH IRB 2017-08-006). 표본은 포함기준을 만족하는 20 명의 환자로 구성하였 다. 환자는 각각 10 명씩 2 개의 군으로 분류하였다(Table 1). 측모두부방사선사진에서 정상 $\left(29^{\circ}<\mathrm{SN}-\mathrm{MP}<37^{\circ}\right)$, 혹은 발산형 성장 $\left(\mathrm{SN}-\mathrm{MP}>37^{\circ}\right)$ 양상을 나타내는 수치 를 보이며, 비발치 교정 치료 받은 경우의 환자들, 좋은 구강 위생을 유지하고 있으며, 악관절 증상이 없는 환자 를 포함하였다. 치료 초기 발산형 안모를 보인 환자 군과 중간형 안모를 보인 환자군으로 분류하였다. 두 군 모두 에서 골격성 임시 고정원을 이용한 pendulum appliance 를 이용하여 단기간 미치는 두개안면 영역의 영향을 평 가하고자 하였다.

임시 고정원을 이용한 pendulum 장치 설치를 위해 국 소마취 하에 1 단계 수술로 구개의 3 번째 구개추벽에 1.6 $\times 8 \mathrm{~mm}$ 미니스크류 2 개를 식립한 뒤 제 2 대구치에 밴드 와 pendulum 스프링으로 연결하여 제작하였다. 식립 위 치는 구개골 정중봉합의 측방이 골질이 가장 우수하므 로 선택되었다. ${ }^{7}$ Pendulum 스프링은 0.032-in SS round wire로 제작하였으며, 작은 수평 조절 루프와 폐쇄형 helix로 구성하였으며, 임시 고정원에 접착 레진으로 고

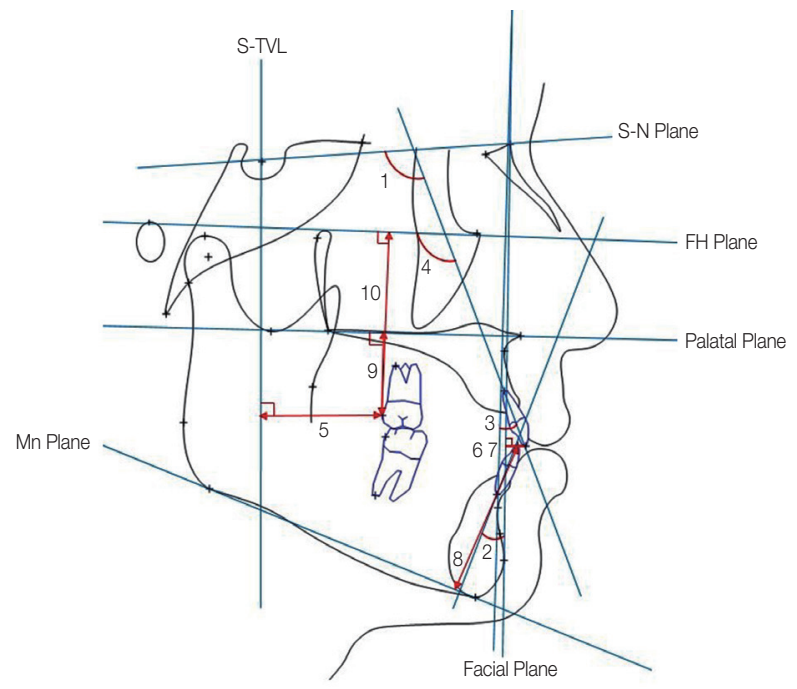

Fig. 2. (1) U1 to SN (degree), (2) L1 to NB (degree), (3) U1 to NA (degree), (4) U1 to FH Plane (degree), (5) S-TVL to U6d $(\mathrm{mm}),(6) \mathrm{L} 1$ to Facial plane $(\mathrm{mm}),(7)$ U1 to Facial plane $(\mathrm{mm}),(8) \mathrm{L} 1$ to $\mathrm{Mn}$ Plane $(\mathrm{mm}),(9) \mathrm{FH}$ Plane to U6d (mm), (10) Palatal plane to U6d $(\mathrm{mm}),(11)$ FH Plane: Po - Or, (12) Palatal Plane: ANS - PNS, (13) Mn Plane: Me - Go, (14) Facial Plane: N - Po.
정하였다. 스프링은 구치 밴드의 lingual sheath 에 삽입 한다. 임시 고정원이 구개골의 지지를 얻기 때문에 절대 적인 구치의 후방이동이 가능하다. ${ }^{6-9}$ 구치 밴드는 장치 시적 전에 접착하였으며, 스프링의 활성은 구개면의 중 심선에 평행하도록 하였으며, 힘은 $300 \mathrm{~g}$ 을 적용하였다. 환자는 1 달 주기로 내원하도록 하였으며, 장치를 점검하 였다. 재활성이 필요할 경우, lingual sheath에서 제거한 후 weingart 플라이어를 이용하여 시행하였다(Fig. 1).

각 환자의 측모두부방사선 사진을 치료 시작 전(T1)과 후(T2)에 나누어 채득하였다. 모든 선그리기 및 계측 과 정 은 한 명의 조사자에 의해 이루어졌다. 수직 기준선은 진성 수직선으로 설정하였다(Fig. 2, 3).

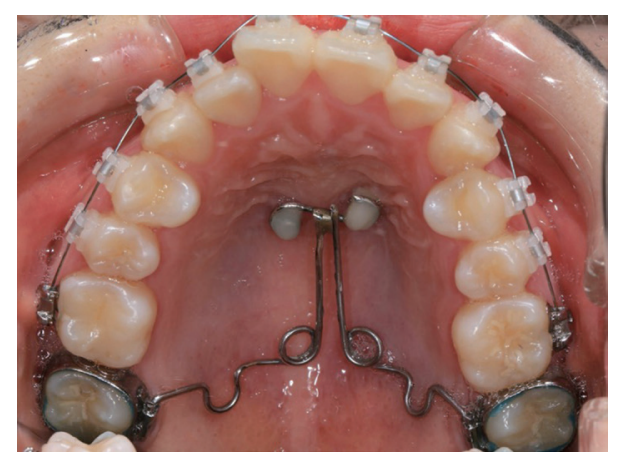

Fig. 1. Pendulum appliance.

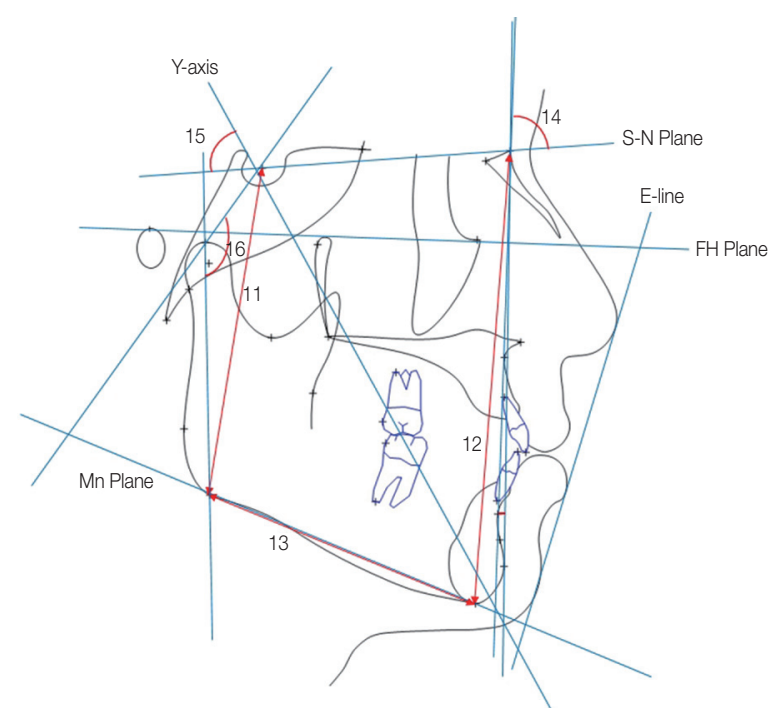

Fig. 3. (11) AFH (mm), (12) PFH (mm), (13) Body length (mm), (14) SNPo (degree), (15) Y axis to SN (degree), (16) Articular angle (degree). ODI: Mn. Plane-AB plane + FH plane-palatal plane (degree); IMPA: Mn plane - long axis of Mn 1 (degree); FMA: FH plane - Mn plane (degree); Facial Convexity: N-A-Pog (degree). 
각 환자의 측모 두부 방사선 사진상에서 중첩 등으로 인해 상악 제 1 대구치의 선그리기 및 계측과정의 정확성 이 의심스러운 경우, 치료 전 채득한 석고 모형과 치료 종 료시 채득한 석고 모형의 계측치(중절치-제 1 대구치 원심 까지 거리)를 참고하여 상악 제1대구치 위치를 설정하였 다(Fig. 4).

본 연구의 표본에서 성장량을 배제하기 위하여 중첩된 두 방사선 사진에서 성장에 의한 절치의 전방이동은 치 료 전후 중첩에서 발생한 거리만큼 대구치의 후방 이동 양 결과에서 반영하여 측정하였으며 통계처리를 시행하 였다(Fig. 5).

Windows용 SPSS 21.0 program을 이용하여 통계분석 하였다. 각 군의 평균과 표준편차는 기술통계를 이용하 였으며, 정규성 검정을 위해 Kolmogorov-Smirnov test 를 사용하였다. 정규분포를 따랐으므로 치료 전 비교를

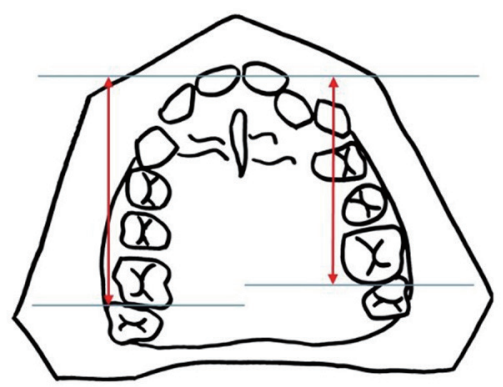

Fig. 4. Model analysis: calculation of distalized amount of $1^{\text {st }}$ molar: different distance between Lt., Rt. side.

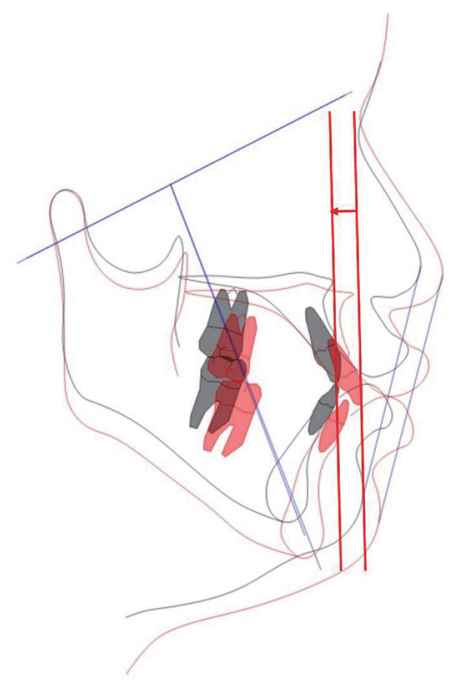

Fig. 5. Exclusion method of growth amount: different incisal position due to growth.
위해 Independent t-test를 시행하였으며, 각 군의 치료 전,후 비교를 위해 Paired t-test를 시행하였다.

\section{결과}

발산형 안모를 보이는 군에서 $\mathrm{L} 1$ to $\mathrm{NB}$ angular $(P<$ 0.05), IMPA ( $P<0.05)$, SN-Po $(P<0.05)$, Anterior Facial height $(P<0.05)$ 는 치료 후 증가하였으며, Stvl U6d $(P<0.05)$, Interincisal angle $(P<0.05)$ 는 치료 후 감소 하였다. 이 역시 상악 구치의 후방이동, 전치의 전방 경 사 증가를 나타내고 있다. 하악 절치가 Nasion-B point 가 이루는 선과 이루는 각의 증가량은 $5.16 \pm 4.18^{\circ}$ 이다. $\mathrm{IMPA}$ 의 증가량은 $4.95 \pm 3.82^{\circ}$ 이다. SN-Po의 증가량 은 $1.04 \pm 1.30^{\circ}$ 이다. Anterior facial height의 증가량은 $4.05 \pm 5.37 \mathrm{~mm}$ 이다. 상악 제 1 대구치의 후방이동양은 $1.98 \pm 1.62 \mathrm{~mm}$ 이며, Interincisal angle의 감소량은 8.06 $\pm 8.85^{\circ}$ 이다(Table 2$)$.

중간형 안모를 보이는 군에서 Stvl-U6d $(P<0.05)$ 는 치료 후 감소했으며, L1 to Mandibular plane $(P<0.05)$ 는 치료 후 증가하였다. 상악 제1대구치는 pendulum 장 치에 의해 후방 이동 되었으며, 하악 절치와 하악 평면과 의 거리가 증가하였다. 상악 제 1 대구치의 후방 이동양은 $2.47 \pm 1.80 \mathrm{~mm}$ 이다. 하악 절치와 하악 평면과의 거리의 증가량은 $1.35 \pm 1.78 \mathrm{~mm}$ 이다(Table 3 ).

치료 양의 군간 비교에 있어서, FMA, SN-GoGn 수치 의 유의한 차이는 유지되고 있으나, ODI 값이 중간형 안 모를 보이는 군에서 증가하였기 때문에, 유의한 차이를 보이고 있다 $(P<0.05)$ (Table 4).

치료 후 군간 비교에서 L1 to NB angular은 발산형 안 모를 보이는 군에서 증가하였으나, 중간형 안모를 보이 는 군에서 유의한 변화가 없었기 때문에 유의한 차이가 존재한다 $(P<0.05)$. IMPA, Facial height ratio도 발산형 안모를 보이는 군에서 유의하게 증가하였기 때문에 차 이를 보이고 있다 $(P<0.05)$. Interincisal angle 은 발산형 안모를 보이는 군에서 유의하게 감소하였기 때문에 변화 량에 유의한 차이가 존재한다 $(P<0.05)$ (Table 5).

Table 1. Sample distribution

\begin{tabular}{lcc}
\hline & N (sample) & Mean age \\
\hline Hyperdivergent group (HG) & 10 & 18.4 \\
Mesocephalic group (MG) & 10 & 17.6 \\
\hline
\end{tabular}


Table 2. Cephalometric variables of hyperdivergent group: pretreatment, posttreatment, difference

\begin{tabular}{lcccc}
\hline & Pretreatment & Posttreatment & Difference & $P$ value \\
\hline L1 to NB angular & $24.67 \pm 6.76^{\circ}$ & $29.83 \pm 4.35^{\circ}$ & $-5.16 \pm 4.18^{\circ}$ & $.004^{*}$ \\
IMPA & $88.74 \pm 5.73^{\circ}$ & $93.69 \pm 4.92^{\circ}$ & $-4.95 \pm 3.82^{\circ}$ & $.003^{*}$ \\
SNPo & $76.35 \pm 3.10^{\circ}$ & $77.39 \pm 2.66^{\circ}$ & $-1.04 \pm 1.30^{\circ}$ & $.032^{*}$ \\
Anterior facial height (AFH) & $127.76 \pm 8.88 \mathrm{~mm}$ & $131.81 \pm 8.55 \mathrm{~mm}$ & $-4.05 \pm 5.37 \mathrm{~mm}$ & $.041^{*}$ \\
stvl U6d & $32.83 \pm 2.25 \mathrm{~mm}$ & $30.85 \pm 2.48 \mathrm{~mm}$ & $1.98 \pm 1.62 \mathrm{~mm}$ & $.004^{*}$ \\
Interincisal angle & $129.83 \pm 11.58^{\circ}$ & $121.77 \pm 5.02^{\circ}$ & $8.06 \pm 8.85^{\circ}$ & $.018^{*}$ \\
\hline
\end{tabular}

significance level: $*(<.05)$.

Table 3. Cephalometric variables of mesocephalic group: pretreatment, posttreatment, difference

\begin{tabular}{lcccc}
\hline & Pretreatment & Posttreatment & Difference & $P$ value \\
\hline stvl U6d & $33.60 \pm 3.78 \mathrm{~mm}$ & $31.13 \pm 4.19 \mathrm{~mm}$ & $2.47 \pm 1.80 \mathrm{~mm}$ & $.002^{*}$ \\
L1 to mandibular plane & $40.06 \pm 2.51 \mathrm{~mm}$ & $41.42 \pm 1.69 \mathrm{~mm}$ & $-1.36 \pm 1.79 \mathrm{~mm}$ & $.040^{*}$ \\
\hline
\end{tabular}

significance level: $*(<.05)$.

Table 4. Differences of treatment amount between two groups (HG, MG)

\begin{tabular}{llc}
\hline & $P$ value & $\begin{array}{c}\text { Mean difference } \\
(\mathrm{HG}-\mathrm{MG})\end{array}$ \\
\hline ODI & $0.046^{*}$ & $-5.583^{\circ}$ \\
FMA & $0.021^{*}$ & $4.224^{\circ}$ \\
SN-GoGn & $0^{*}$ & $7.252^{\circ}$ \\
\hline
\end{tabular}

significance level : $*(<.05)$.

\section{총괄 및 고찰}

구치의 후방이동시 여러 가지 구외, 구내 장치가 사용 되어왔다. ${ }^{18}$ Hilgers의 pendulum 장치는 구내 장치로서 구치 후방이동시 상악 소구치, 절치, 구개면의 전방 부위 를 고정원으로 사용하였다. ${ }^{19,20}$ 구치부의 후방 이동에는 효율적이나 근심 방향의 힘 또한 발생하여, 고정원의 손 실이 발생할 수 있다. ${ }^{5}$ 임시 고정원의 사용은 이러한 근 심방향의 고정원 상실이 거의 발생하지 않도록 함으로써 치료에 유의한 차이를 만들어낼 수 있다. ${ }^{6-17}$

Triaca 등 ${ }^{21}$, Wehrbein 등 ${ }^{22}$ 은 경구개의 정중시상부위가 임시 고정원의 위치로 적절하다고 하였으며, 현재 널리 받아들여지고 있다. 정중부위 근처 영역 역시 식립에 적 절하다고 판단된다. ${ }^{7}$ 이번 연구에서는 직경 $1.6 \mathrm{~mm}$, 길이 $8 \mathrm{~mm}$ 의 miniscrew를 정중부위 양측에 전, 후방 거리차 를 두고 식립하였으며, 이는 장치의 상, 하 방향의 회전을
Table 5. Posttreatment comparison between two groups (HG, MG)

\begin{tabular}{lcc}
\hline & $P$ value & $\begin{array}{c}\text { Mean difference } \\
(\mathrm{HG}-\mathrm{MG})\end{array}$ \\
\hline L1 to NB angular & $0.042^{*}$ & $-3.839^{\circ}$ \\
IMPA & $0.017^{*}$ & $-4.241^{\circ}$ \\
Facial height ratio & $0.022^{*}$ & $-0.012^{\circ}$ \\
Interincisal angle & $0.049^{*}$ & $7.305^{\circ}$ \\
\hline significance level $: *(<.05)$. & &
\end{tabular}

억제하며, 견고한 고정원을 얻기 위함이다.

이전의 연구에서 pendulum 형태의 장치는 상악 구치 의 유의한 후방 경사를 야기한다. ${ }^{9}$ 평균 후방 경사 양은 $1.8 \mathrm{~mm}$ 이동시 $1.5^{\circ}$ 이며 이는 $1 \mathrm{~mm}$ 이동시 $0.8^{\circ}$ 후방경 사로 환산된다. ${ }^{5}$ 순측에서 연속 호선을 삽입함으로써 구 치의 후방 경사를 감소시킬 수 있다. ${ }^{23}$ 또한, 후방이동으 로 발생한 공간으로 소구치, 견치, 절치들이 뒤이어 후방 이동 됨에 따라 구치의 경사 및 위치에 영향을 주게 되며, 이로 인해 후방 경사양이 감소할 수 있다.

Pendulum 형태의 장치로 구치를 후방이동할 경우 수 직적으로 정출, 함입이 발생하는 데에 있어 논란이 존재 한다.이전의 연구에서 기존의 pendulum 장치를 사용할 경우 제 1 대구치의 함입이 발생하였으나, 유의하지 않다 고 하였다. ${ }^{3,4}$ 대조적으로 다른 연구에서 구치의 정출을 보고하였으나 이 역시 유의하지 않다고 하였다. ${ }^{9,23}$ Byloff 등은 $3.39 \pm 1.25 \mathrm{~mm}$ 후방 이동시 $1.68 \pm 1.33 \mathrm{~mm}$ 의 구 
치부 함입을 보고하였다. ${ }^{24}$ 이러한 함입을 혀에 의한 영 향, 강하게 고정된 장치에 의한 수직적 성장의 억제와 장 치 자체의 디자인에 의한 잠재적 영향으로 판단하였다. 마 등은 $1.8 \mathrm{~mm}$ 후방 이동시 원심 교두의 $1.1 \mathrm{~mm}$ 의 함 입을 보고하였다. ${ }^{5}$ 이 연구에서 구개면에서 얻은 절대적 고정원이 구치에 힘을 가하고 있기 때문이라고 판단하였 다.

이번 연구에서 측모 두부방사선 사진 분석에서 수직적 인 지표에서 유의한 차이를 보이는 두 군에서 골격 지지 pendulum 장치의 영향을 분석하고자 하였다. Pendulum 장치와 교정치료로 인해 치성 변화들을 관찰하였으나 수 직적인 지표의 유의차는 치료 후에도 유지되었다. 중간 형 안모에서 상악 구치부의 정출은 유의하지 않았으며 전체 골격에 있어서 수직적으로도 변화가 없었다. 발산형 안모에서 상악 구치부의 함입은 유의하지 않았으며 전체 골격에 있어서 수직적으로도 변화가 없었다. 중간형 안 모에서 치료 종료 후 ODI 값은 증가하여 피개교합이 증 가된 양상을 확인할 수 있었다. 이전의 연구와 유사한 결 과를 얻을 수 있었는데, pendulum 장치를 사용할 경우 구치부의 정출은 관찰되지 않았으며, 이로 인해 안모의 수직적인 부분에도 유의한 영향을 미치지 않았다.

\section{결론}

골격 형태에 따른 차이로 발산형 안모군(HG)은 구치 부 후방이동과 관련하여 하악 전치의 순측 경사가 유의 하게 나타났다. 중간형 안모군(MG)은 구치부의 유의한 이동만 나타났다. 전치의 순측 이동은 유의성이 없었다. 본 논문에서 Pendulum 장치는 수직적인 안모 형태에 유 의한 영향을 주지 않으며, 악화시키지 않았다.

\section{Acknowledgements}

이 연구는 2017학년도 단국대학교 대학연구비 지원으 로 연구되었음.

\section{References}

1. Bolla E, Muratore F, Carano A, Bowman SJ. Evaluation of maxillary molar distalization with the distal jet: a comparison with other contemporary methods. Angle Orthod 2002;72:481-94.

2. Burhan AS. Combined treatment with headgear and the Frog appliance for maxillary molar distalization: a randomized controlled trial. Korean J Orthod 2013;43:101-9.

3. Fuziy A, Rodrigues de Almeida R, Janson G, Angelieri F, Pinzan A. Sagittal, vertical, and transverse changes consequent to maxillary molar distalization with the pendulum appliance. Am J Orthod Dentofacial Orthop 2006;130:502-10.

4. Patel MP, Janson G, Henriques JF, de Almeida RR, de Freitas MR, Pinzan A, de Freitas KM. Comparative distalization effects of Jones jig and pendulum appliances. Am J Orthod Dentofacial Orthop 2009; 135:336-42.

5. Mah SJ, Kim JE, Ahn EJ, Nam JH, Kim JY, Kang YG. Analysis of midpalatal miniscrew-assisted maxillary molar distalization patterns with simultaneous use of fixed appliances: a preliminary study. Korean J Orthod 2016;46:55-61.

6. Escobar SA, Tellez PA, Moncada CA, Villegas CA, Latorre CM, Oberti G. Distalization of maxillary molars with the bone-supported pendulum: a clinical study. Am J Orthod Dentofacial Orthop 2007; 131:545-9.

7. Onçağ G, Seçkin O, Dinçer B, Arikan F. Osseointegrated implants with pendulum springs for maxillary molar distalization: a cephalometric study. Am J Orthod Dentofacial Orthop 2007;131:16-26.

8. Onçağ G, Akyalçin S, Arikan F. The effectiveness of a single osteointegrated implant combined with pendulum springs for molar distalization. Am J Orthod Dentofacial Orthop 2007;131:277-84.

9. Polat-Ozsoy O, Kircelli BH, Arman-Ozçirpici A, Pektaş ZO, Uçkan S. Pendulum appliances with 2 anchorage designs: conventional anchorage vs bone anchorage. Am J Orthod Dentofacial Orthop 2008;133:339.

10. Fudalej P, Antoszewska J. Are orthodontic distalizers reinforced with the temporary skeletal anchorage devices effective? Am J Orthod Dentofacial Orthop 2011;139:722-9.

11. Grec RH, Janson G, Branco NC, Moura-Grec PG, Patel MP, Castanha Henriques JF. Intraoral distalizer effects with conventional and skeletal anchorage: a meta-analysis. Am J Orthod Dentofacial Orthop 2013;143:602-15. 
12. Keles A, Erverdi N, Sezen S. Bodily distalization of molars with absolute anchorage. Angle Orthod 2003;73:471-82.

13. Kinzinger GS, Wehrbein H, Diedrich PR. Molar distalization with a modified pendulum appliancein vitro analysis of the force systems and in vivo study in children and adolescents. Angle Orthod 2005;75:558-67.

14. Caprioglio A, Fontana M, Longoni E, Cozzani M. Long-term evaluation of the molar movements following Pendulum and fixed appliances. Angle Orthod 2013;83:447-54.

15. Sar C, Kaya B, Ozsoy O, Özcirpici AA. Comparison of two implant-supported molar distalization systems. Angle Orthod 2013;83:460-7.

16. Kang JM, Park JH, Bayome M, Oh M, Park CO, Kook YA, Mo SS. A three-dimensional finite element analysis of molar distalization with a palatal plate, pendulum, and headgear according to molar eruption stage. Korean J Orthod 2016;46:290-300.

17. Kärcher H, Byloff FK, Clar E. The Graz implant supported pendulum, a technical note. J Craniomaxillofac Surg 2002;30:87-90.

18. Yu IJ, Kook YA, Sung SJ, Lee KJ, Chun YS, Mo SS.
Comparison of tooth displacement between buccal mini-implants and palatal plate anchorage for molar distalization: a finite element study. Eur J Orthod 2014;36:394-402.

19. Hilgers JJ. The pendulum appliances for Class II non-compliance therapy. J Clin Orthod 1992;26: 706-14.

20. Hilgers JJ, Bennet RK. The pendulum appliance: creating the gain. Clin Impressions 1994;3:14-23.

21. Triaca A, Antonini M, Wintermantel E. Ein neus titan-flachschrauben-implantat zur orthodontischen verankerung am anterioren gaumen. Inf Orthod Kieferorthop 1992;24:251-7.

22. Wehrbein H, Merz BR, Diedrich P. Palatal bone support for orthodontic implant anchorage-a clinical and radiological study. Eur J Orthod 1999;21:6570.

23. Kircelli BH, Pektaş ZO, Kircelli C. Maxillary molar distalization with a bone-anchored pendulum appliance. Angle Orthod 2006;76:650-9.

24. Byloff FK, Darendeliler MA. Distal molar movement using the pendulum appliance. Part 1: Clinical and radiological evaluation. Angle Orthod 1997;67: 249-60. 


\section{골격고정원을 이용한 Pendulum 장치가 두개 안면의 수직적 요소에 미치는 효과 분석}

\section{이진우*}

단국대학교 치과대학 치과교정과학교실

목적: 골격성 고정원의 사용으로 고정원이 보강된 Pendulum 장치가 환자의 두개 안면 요소의 수직적인 부분에 미치는 영향을 분석하고자 하였다.

연구 재료 및 방법: 골격성 고정원과, pendulum을 이용하여 비발치 치료를 시행한 환자 중, 발산형 안모(SN-MP $>37^{\circ}$ ) 와 중간형 안모 $\left(29^{\circ}<\mathrm{SN}-\mathrm{MP}<37^{\circ}\right)$ 각각 10 명씩 분류하여 치료의 단기적 효과에 대해 분석하였다.

결과 및 결론: 골격 형태에 따른 차이로 발산형 안모군(HG)은 구치부 후방이동과 관련하여 하악 전치의 순측 경사가 유 의하게 나타났다 $(P<0.05)$. 중간형 안모군 $(\mathrm{MG})$ 은 구치부의 유의한 이동만 나타났다 $(P<0.05)$. 전치의 순측 이동은 유 의성이 없었다. 본 논문에서 Pendulum 장치는 수직적인 안모 형태에 유의한 영향을 주지 않으며, 악화시키지 않았다.

(구강회복응용과학지 2018;34(1):10-6)

주요어: 골격성 고정원; Pendulum 장치; 두개 안면의 수직적 요소 